\title{
Recent approaches to
}
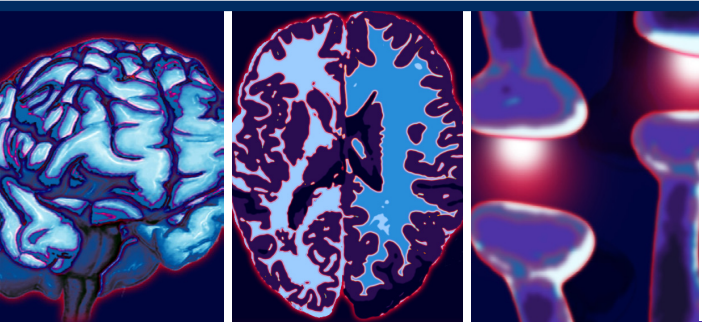

\section{pharmacotherapy of personality disorders}

\author{
Silvio Bellino ${ }^{+1}$, Camilla Rinaldi', Paola Bozzatello' \& Filippo Bogetto'
}

\section{Practice points}

- Pharmacotherapy of personality disorders should be considered a symptom-focused treatment, targeting dimensions of affective dysregulation, impulsive-behavioral dyscontrol and cognitive-perceptual symptoms.

- To date, randomized controlled trials have been performed in samples of patients with antisocial personality disorder, schizotypal personality disorder and borderline personality disorder (BPD). However, the great majority of these trials have been conducted in samples with BPD.

- There is some evidence that mood stabilizers (topiramate, valproate and lamotrigine), second-generation antipychotics (olanzapine, aripiprazole), and omega-3 fatty acids can be useful for the treatment of affective symptoms and impulsive-behavioral dyscontrol in BPD patients.

- Antipsychotics produced an improvement of psychotic-like symptoms both in patients with BPD and schizotypal personality disorder.

- Selective serotonin reuptake inhibitors were found to be effective in decreasing depressed mood, anxiety, and anger in BPD patients, mainly with a comorbid major depressive episode. However, recent evidence no longer supports their use as first-line treatment of affective symptoms and impulsive-behavioral dyscontrol in BPD.

- Present studies suffer from important methodological limitations. Thus, further investigations are needed to confirm available findings.

SUMMARY A growing number of studies on pharmacotherapy of personality disorders have been performed. This article considers controlled trials conducted between 1990 and 2010, and is directed toward the treatment of personality disorders. Data on borderline personality disorder (BPD), antisocial personality disorder and schizotypal personality disorder (STPD) were collected and discussed, in order to provide indications for clinical practice. Concerning antisocial personality disorder and STPD, available evidence is too sparse to propose treatment recommendations. As for BPD, there is some evidence that mood stabilizers (topiramate, valproate, and lamotrigine), second-generation antipsychotics (olanzapine, aripiprazole), and omega- 3 fatty acids can be useful to treat affective symptoms

'Center for Personality Disorders, Unit of Psychiatry 1, Department of Neurosciences, University of Turin, via Cherasco 11, 10126, 
and impulsive-behavioral dyscontrol. Antipsychotics showed positive effects on cognitive symptoms both in patients with BPD and STPD. Selective serotonin reuptake inhibitors were found effective in decreasing depressed mood, anxiety and anger in BPD patients, mainly in subjects with a concomitant affective disorder. Effects of antidepressants on impulsive behaviors are uncertain. Further studies are needed to improve methods of trials and confirm these findings.

Personality disorders (PDs) are defined as enduring patterns of inner experience and behavior causing distress, which lead to maladaptive functioning in the areas of emotion, cognition, interpersonal relationships and impulse control [1]. Since the 1980s there has been increasing recognition that $\mathrm{PDs}$ can be considered as syndromes of interacting dimensional traits that arise from psychosocial development and/or biological vulnerability [2]. Personality dimensions acquired through social and cultural learning are termed character, whereas those believed to have a biological origin, genetically determined or acquired from overt injury to the CNS, are traditionally referred to as temperament. Temperament involves the biological regulation of cognition, perception, information processing, affect, and impulse, which is carried out by neurotransmitter systems. A pharmacological approach to treatment of PDs is based on the ability of medications to modify neurotransmitter functions that mediate expression of state symptoms and trait vulnerabilities related to personality dimensions.

According to Soloff's model [3,4], adopted by American Psychiatric Association (APA) guidelines for the treatment of borderline personality disorder (BPD) [1], pharmacotherapy of PDs may be reframed as symptom-specific treatment, focused on a few target dimensions, such as affective dysregulation, cognitive-perceptual symptoms and impulsive-behavioral dyscontrol.

Pharmacotherapy is an important adjunctive treatment in the overall management of patients with severe PDs, but is not a primary treatment for problems of character or maladaptive interpersonal relationships, which are the main focus of psychotherapy. Thus, medication should only be part of a comprehensive treatment plan including psychotherapy and social work, which should be developed considering the individual psychopathology, severity of illness and functioning.

Pharmacotherapy of PDs is still a relatively new and evolving clinical practice. It is important to note that the US FDA has not approved any medication for the treatment of PDs yet.
Randomized controlled trials (RCTs) on treatment of PDs are limited and the great majority of these trials have been conducted in patients with borderline PD. Nevertheless, these results have made possible the development of treatment guidelines that provide detailed recommendations for clinicians dealing with PD patients. Before presenting and discussing contents of available treatment guidelines, we will review double-blind randomized comparisons of drug versus placebo or drug versus drug published between 1990 and 2010 and directed at the treatment of PDs. Available controlled studies are focused on BPD, antisocial personality disorder (ASPD) and schizotypal personality disorder (STPD). Results of studies on each cluster of PDs are separately described.

\section{Treatment of STPD}

Schizotypal PD is generally considered a schizophrenia spectrum disorder $[5,6]$. Similarities between STPD and schizophrenia in phenomenology and biological correlates have provided the rationale for testing the efficacy of classical neuroleptics (flupentixol, thiothixene and haloperidol) in patients with STPD since 1980 [7-9]. Patients in these studies gained modest improvement after treatment with low doses of neuroleptics, with the greatest effects on psychotic-like symptoms and anxiety.

Concerning second-generation antipsychotics, few data are available $[10,11]$ and only two RCTs on risperidone have been published [12,13].

Koenigsberg et al. performed a 9-week RCT on 25 STPD patients (five subjects had comorbid $\mathrm{BPD}$ ), randomly assigned to risperidone $(0.25-2.00 \mathrm{mg} /$ day $)$ or placebo [12]. Patients in the risperidone group showed a significant decline in the Positive and Negative Syndrome Scale (PANSS) total, negative, positive, and general scores, compared with placebo. Significant differences were not found with the Schizotypal Personality Disorder Questionnaire (SPQ), the Hamilton Depression Rating Scale (HAMD) and the Clinical Global Impression (CGI). Moreover, seven of the 15 patients in the risperidone group dropped out because of side effects. In 
recent years, there has been growing interest for treatment of cognitive performances measured by neuropsychological tests in schizophrenia spectrum disorders, such as STPD. McClure et al. enrolled 31 STPD patients, randomly assigned to risperidone $(0.25-2.00 \mathrm{mg} / \mathrm{day})$ or placebo, in order to evaluate the effects of risperidone on their cognitive performance [13]. Several patients in both groups dropped out and only 20 subjects completed all 12 weeks of the trial. There were no significant differences between the two treatment groups in improvement of neuropsychological functions (spatial and verbal working memory, vigilance, spatial memory, work list learning) from baseline. More encouraging results on these outcome measures were obtained by the same research group [14,15] using dopamine and adrenaline agonists. McClure et al. performed a double-blind, placebo-controlled trial of guanfacine on 29 STPD patients, supporting its efficacy in improving context processing [14]. In another RCT, they administered pergolide to 25 patients with STPD and found a significant improvement in visual spatial working memory, executive functioning, verbal learning and memory [15].

In conclusion, preliminary studies performed in STPD patients (Table 1) suggest a reduction of psychotic-like symptoms with antipsychotics and an improvement of cognitive performances measured by neuropsychological tests with dopamine and adrenaline agonists. Nevertheless, most studies suffer from high drop-out rates because of considerable sensitivity to side effects in this population. Moreover, some patients in these studies had concomitant BPD [8-10,12]. So, it remains unclear whether the reported improvements were due to the medications' effects on BPD-related symptoms.

\section{Pharmacotherapy of cluster B PDs}

Newer therapies for ASPD have received preliminary testing. Nevertheless most studies of patients with cluster B PDs are focused on treatment of BPD.

Results of controlled studies on the efficacy of each class of drugs are separately reviewed, in order to make clear the different level of evidence.

\section{Treatment of BPD \\ - Antidepressants}

A considerable number of open-label trials and RCTs have been performed to assess the efficacy of antidepressants in the treatment of affective lability, impulsivity and aggressiveness in BPD samples. The following groups of antidepressants have been evaluated: tricyclic antidepressants, monoamino-oxidase inhibitors (MAOIs), selective serotonin reuptake inhibitors (SSRIs), and serotonin and norepinephrine reuptake inhibitors (SNRIs). Concerning tricyclic antidepressants and MAOIs, available data [16-19] suggest that the efficacy of these drugs in patients with BPD is limited, with main effects on symptoms of depression. The risk of behavioral toxicity and the potential lethality support the preferential use of SSRIs or SNRIs to treat these patients.

\section{Selective serotonin reuptake inhibitors}

Six RCTs testing the efficacy of SSRIs have been conducted so far: five studies on fluoxetine [20-24], one study on fluvoxamine (Table 2) [25].

Salzmann and colleagues published a 12 -week double-blind trial of fluoxetine (20-60 mg/day) in 27 patients with BPD or bipolar traits,

Table 1. Double-blind randomized trials in the treatment of schizotypal personality disorder.

\begin{tabular}{|c|c|c|c|c|c|}
\hline Study (year) & Agents & Study design & Subjects & Results (primary outcome) & Ref. \\
\hline McClure et al. (2007) & $\begin{array}{l}\text { Guanfacine }(\leq 2 \mathrm{mg} / \text { day }) \\
\text { versus placebo }\end{array}$ & $\begin{array}{l}\text { RCT } \\
4 \text { weeks }\end{array}$ & 29 STPD patients & $\uparrow$ context processing ability & [14] \\
\hline
\end{tabular}


Table 2. Double-blind randomized trials of selective serotonin reuptake inhibitors in the treatment of borderline

personality disorder.

\begin{tabular}{|c|c|c|c|c|c|}
\hline Study (year) & Agents & Study design & Subjects & Results (primary outcome) & Ref. \\
\hline Markovitz (1995) & $\begin{array}{l}\text { Fluoxetine } \\
(20-80 \mathrm{mg} / \text { day }) \\
\text { versus placebo }\end{array}$ & $\begin{array}{l}\text { RCT } \\
14 \text { weeks }\end{array}$ & $\begin{array}{l}17 \text { BPD patients with } \\
\text { concomitant Axis I affective } \\
\text { and anxiety disorders }\end{array}$ & $\begin{array}{l}\downarrow \text { anxiety and depression } \\
\downarrow \text { global symptoms }\end{array}$ & [20] \\
\hline Salzmann et al. (1995) & $\begin{array}{l}\text { Fluoxetine } \\
\text { ( } 20-60 \mathrm{mg} / \text { day) } \\
\text { versus placebo }\end{array}$ & $\begin{array}{l}\text { RCT } \\
12 \text { weeks }\end{array}$ & $\begin{array}{l}27 \text { BPD patients } \\
\text { with a good level } \\
\text { of functioning, } \\
\text { no Axis I or II comorbidity }\end{array}$ & $\begin{array}{l}\downarrow \text { anger } \\
\uparrow \text { global functioning }\end{array}$ & [21] \\
\hline $\begin{array}{l}\text { Coccaro and Kavoussi } \\
\text { (1997) }\end{array}$ & $\begin{array}{l}\text { Fluoxetine } \\
(20-60 \mathrm{mg} / \text { day }) \\
\text { versus placebo }\end{array}$ & $\begin{array}{l}\text { RCT } \\
12 \text { weeks }\end{array}$ & $\begin{array}{l}40 \text { patients with PDs ( } 33 \% \\
\text { BPD, } 25 \% \text { female), impulsive- } \\
\text { aggressive behaviors and } \\
\text { comorbidity with dysthymic } \\
\text { disorder, anxiety disorders or } \\
\text { substance abuse }\end{array}$ & $\begin{array}{l}\downarrow \text { irritability } \\
\downarrow \text { impulsive-aggression } \\
\uparrow \text { global functioning }\end{array}$ & [22] \\
\hline Simpson et al. (2004) & $\begin{array}{l}\text { Fluoxetine ( } 40 \mathrm{mg} / \text { day) } \\
+ \text { DBT versus DBT + } \\
\text { placebo }\end{array}$ & $\begin{array}{l}\mathrm{RCT} \\
12 \text { weeks }\end{array}$ & $\begin{array}{l}25 \text { female BPD patients, } \\
\text { no bipolar disorder }\end{array}$ & $\begin{array}{l}\text { No significant effects on } \\
\text { depression, anxiety, anger, } \\
\text { dissociation and global } \\
\text { functioning }\end{array}$ & [23] \\
\hline Zanarini et al. (2004) & $\begin{array}{l}\text { Fluoxetine ( } 15 \mathrm{mg} / \text { day) } \\
\text { versus olanzapine } \\
\text { ( } 2.5 \mathrm{mg} / \text { day) versus } \\
\text { OFC }\end{array}$ & $\begin{array}{l}\mathrm{RCT} \\
8 \text { weeks }\end{array}$ & $\begin{array}{l}45 \text { female BPD patients, } \\
\text { no affective disorder }\end{array}$ & $\begin{array}{l}\text { Olanzapine and OFC greater } \\
\text { than fluoxetine on impulsive- } \\
\text { aggression and depression }\end{array}$ & [24] \\
\hline Rinne et al. (2002) & $\begin{array}{l}\text { Fluvoxamine } \\
(150-250 \mathrm{mg} / \text { day }) \\
\text { versus placebo }\end{array}$ & $\begin{array}{l}\text { RCT } \\
6 \text { weeks } \\
\text { Crossover }\end{array}$ & $\begin{array}{l}38 \text { female BPD patients, } \\
\text { comorbidity with mood and } \\
\text { anxiety disorders }\end{array}$ & $\begin{array}{l}\downarrow \text { rapid mood shift } \\
\text { No effects on aggression } \\
\text { and impulsivity }\end{array}$ & [25] \\
\hline
\end{tabular}

evaluating effects on global functioning, anger and depression [21]. Patients had a good level of functioning (baseline Global Assessment of Symptoms [GAS] scores in the 70s) and did not present comorbidity with Axis I or II disorders. In a primary analysis, only the anger subscale of the Profile of Mood States (POMS) and the GAS yielded a statistical improvement over placebo in the 22 patients completing the trial. In a post hoc analysis with correction for the strong placebo effect, statistically significant differences between treatment conditions were obtained with respect to anger and aggression, which appeared to be independent of depression.

Markovitz conducted a 14-week RCT of fluoxetine (20-80 $\mathrm{mg} / \mathrm{day})$ in a group of 17 patients with BPD and high co-occurrence of affective/anxiety disorders and somatic symptoms [20]. Patients receiving fluoxetine improved significantly more than those receiving placebo on measures of depression, anxiety and global symptoms. Measures of impulsive-aggression were not included in this study. Comorbidity with affective and anxiety disorders limits interpretation of results, because SSRIs are effective for these disorders independently of BPD.

A double-blind placebo-controlled study by Coccaro and Kavoussi focused attention on impulsive-aggression as a dimensional construct, found across PD categories, but especially characteristic of BPD and other cluster B PDs [22]. They enrolled a mixed sample of $40 \mathrm{PD}$ patients (approximately a third with a Diagnostic and Statistical Manual of Mental Disorders [DSM]III-R diagnosis of BPD), all with impulsiveaggressive behavior and irritability (the female group constituted only a quarter of the total sample). Comorbid major depression or bipolar disorder were excluded, but dysthymic disorder, anxiety disorders, alcohol and substance abuse were common. Subjects were randomly assigned to fluoxetine (20-60 mg/day) or placebo in a ratio 2:1 for a 12-week trial. A significant improvement with respect to impulsive-aggressive behavior was seen in favor of fluoxetine after 10 weeks of treatment, but global improvement was already significant at week 4 and irritability decreased at week 6 . 
Rinne et al. tested the efficacy of fluvoxamine (mean dose $166 \mathrm{mg} /$ day) versus placebo in 38 female patients with BPD [25]. The study was a double-blind controlled trial of 6 weeks, followed by a 6 -week crossover. Significant improvement was found in the scale scores for rapid mood shifts, with the most improvement in the first 6 weeks. By contrast, no difference between the fluvoxamine and placebo group was observed with regard to the effect on impulsivity and aggression scores. The authors suggested that effects on anger and impulsivity may be related to gender.

Simpson et al. studied the effect of 12 weeks fluoxetine $(40 \mathrm{mg} /$ day $)$ in a placebo-controlled trial in 25 females with BPD during dialectical behavior therapy (DBT) [23]. Combining fluoxetine did not show any additional benefit on selfreport measures of depression, anxiety, anger, dissociation and global functioning.

Zanarini et al. compared fluoxetine (mean dose $15 \mathrm{mg} /$ day) with olanzapine and a combination treatment of both drugs with respect to mood symptoms and impulsive-aggressive behavior in 45 female BPD patients [24]. There was no placebo control group. Olanzapine monotherapy and the combination were found to be superior to fluoxetine monotherapy. It is important to note that, for severe PD, an unusually low dose of fluoxetine was used, which might explain the lack of efficacy of fluoxetine.

In summary, there is some evidence that SSRIs are effective in decreasing affective symptoms [25], specifically depressed mood [20,21], anxiety [20], and anger [21,22] in BPD patients. Effects on impulsive-aggression appear independent of effects on affective symptoms and may be related to male gender.

\section{- Mood stabilizers}

Several RCTs have investigated the efficacy of mood stabilizers in treatment of affective dysregulation and behavioral dyscontrol of BPD patients (Table 3).

\section{Lithium}

The only RCT of lithium in BPD is reported by Links et al. [19]. In a crossover study, the effects of lithium and desipramine were compared in 17 patients. A significant improvement of anger and suicidality, but not of mood symptoms, was found in favor of the lithium therapy. Although this evidence is not sufficient to support the indication of lithium for these patients, the risk of toxicity and the need for regular blood level controls are significant limitations to the use of this drug in the BPD population.

\section{Carbamazepine}

De la Fuente and Lotstra conducted a RCT of carbamazepine in 20 BPD outpatients without any Axis I comorbidity [26]. Treatment lasted for 31 days. Carbamazepine doses were adjusted to yield plasma levels in the low therapeutic range. There were no significant differences between carbamazepine and placebo on measures of affective symptoms, behavioral dyscontrol or global assessment. Moreover, two patients receiving carbamazepine dropped out because of acting out behaviors. Considering the limited efficacy on BPD symptoms shown so far by this drug and the risk of severe adverse effects (e.g., exacerbation of behavioral dyscontrol and agranulocitosis), it should be considered a questionable treatment option.

\section{Valproate}

Hollander $e t$ al. performed a preliminary double-blind trial of valproate sodium (medium plasma concentration $80 \mu \mathrm{g} / \mathrm{ml}$ ) in $16 \mathrm{BPD}$ patients, finding marked improvement in global symptomatology, social functioning and BPD features such as depressive symptoms, aggressiveness, irritability and suicidal behavior [27]. The study suffered from a high drop-out rate (ten patients), which accounted for nonsignificant results in the intention to treat analysis.

The same authors [28] tested valproate treatment on a sample of 246 patients with a high degree of aggression (including BPD and other cluster B PDs), confirming its efficacy for treating impulsive-aggressive behavior. More recently, they reported that the effect of valproate in 52 BPD patients from the previous study, was higher among those with high trait impulsivity [29].

Frankenburg and Zanarini conducted a 6-month placebo-controlled study of valproate sodium (plasma concentration $50-100 \mu \mathrm{g} / \mathrm{ml}$ ) in 30 women with comorbidity of BPD and bipolar II disorder [30]. A significant improvement of interpersonal sensitivity, anger, hostility and aggressiveness was found in the valproate group.

In conclusion, valproate is one of the more extensively investigated drugs for treatment of impulsive-aggressive behaviors in BPD. 


\begin{tabular}{|c|c|c|c|c|c|}
\hline Study (year) & Agents & $\begin{array}{l}\text { Study } \\
\text { design }\end{array}$ & Subjects & Results (primary outcome) & Ref. \\
\hline Links et al. (1990) & $\begin{array}{l}\text { Lithium } \\
\text { (986 mg/day) } \\
\text { versus desipramine } \\
\text { versus placebo }\end{array}$ & $\begin{array}{l}\text { RCT } \\
6 \text { weeks } \\
\text { Crossover }\end{array}$ & $\begin{array}{l}17 \text { BPD patients, } \\
\text { all receving concomitant } \\
\text { psychotherapy }\end{array}$ & $\begin{array}{l}\downarrow \text { irritability and anger } \\
\downarrow \text { self-mutilation in favor of lithium } \\
\text { No effects on mood symptoms } \\
\text { High rate of drop-out (10 patients) }\end{array}$ & [19] \\
\hline $\begin{array}{l}\text { De la Fuente and } \\
\text { Lotstra (1994) }\end{array}$ & $\begin{array}{l}\text { Carbamazepine } \\
\text { (plasma level) } \\
\text { versus placebo }\end{array}$ & $\begin{array}{l}\text { RCT } \\
4.5 \text { weeks }\end{array}$ & $\begin{array}{l}20 \text { BPD outpatients, no } \\
\text { Axis I comorbidity }\end{array}$ & $\begin{array}{l}\text { No effects on affective symptoms, } \\
\text { behavioral dyscontrol and } \\
\text { global assessment }\end{array}$ & {$[26]$} \\
\hline $\begin{array}{l}\text { Hollander et al. } \\
\text { (2001) }\end{array}$ & $\begin{array}{l}\text { Valproate sodium (plasma } \\
\text { level) versus placebo }\end{array}$ & $\begin{array}{l}\mathrm{RCT} \\
10 \text { weeks }\end{array}$ & $\begin{array}{l}16 \text { BPD patients, no psychotic } \\
\text { and affective disorders }\end{array}$ & $\begin{array}{l}\text { No significant differences because of } \\
\text { high rate of drop-out ( } 10 \text { patients) }\end{array}$ & {$[27]$} \\
\hline $\begin{array}{l}\text { Hollander et al. } \\
\text { (2003) }\end{array}$ & $\begin{array}{l}\text { Valproate sodium (plasma } \\
\text { level) versus placebo }\end{array}$ & $\begin{array}{l}\text { RCT } \\
12 \text { weeks }\end{array}$ & $\begin{array}{l}96 \text { cluster B PDs with impulsive- } \\
\text { aggression ( } 52 \text { BPD), no } \\
\text { affective disorders }\end{array}$ & $\begin{array}{l}\downarrow \text { irritability } \\
\downarrow \text { impulsive-aggression } \\
\downarrow \text { global severity }\end{array}$ & {$[28]$} \\
\hline $\begin{array}{l}\text { Frankenburg } \\
\text { and Zanarini } \\
(2002)\end{array}$ & $\begin{array}{l}\text { Valproate sodium (plasma } \\
\text { level) versus placebo }\end{array}$ & $\begin{array}{l}\mathrm{RCT} \\
6 \text { months }\end{array}$ & $\begin{array}{l}30 \text { female BPD patients with } \\
\text { concomitant bipolar II disorder }\end{array}$ & $\begin{array}{l}\downarrow \text { interpersonal sensitivity } \\
\downarrow \text { anger and hostility } \\
\downarrow \text { aggressiveness }\end{array}$ & [30] \\
\hline $\begin{array}{l}\text { Nickel et al. } \\
(2004)\end{array}$ & $\begin{array}{l}\text { Topiramate } \\
\text { (50-250 mg/day) } \\
\text { versus placebo }\end{array}$ & $\begin{array}{l}\mathrm{RCT} \\
8 \text { weeks }\end{array}$ & 31 female BPD patients & $\downarrow$ irritability and anger & [31] \\
\hline $\begin{array}{l}\text { Nickel et al. } \\
(2005)\end{array}$ & $\begin{array}{l}\text { Topiramate } \\
(50-250 \mathrm{mg} / \mathrm{day}) \\
\text { versus placebo }\end{array}$ & $\begin{array}{l}\mathrm{RCT} \\
8 \text { weeks }\end{array}$ & 42 male BPD patients & $\downarrow$ irritability and anger & {$[32]$} \\
\hline $\begin{array}{l}\text { Loew et al. } \\
\text { (2008) }\end{array}$ & $\begin{array}{l}\text { Topiramate } \\
(25-200 \mathrm{mg} / \text { day }) \\
\text { versus placebo }\end{array}$ & $\begin{array}{l}\mathrm{RCT} \\
10 \text { weeks }\end{array}$ & $\begin{array}{l}56 \text { female BPD } \\
\text { and mood disorder patients }\end{array}$ & $\begin{array}{l}\downarrow \text { somatization symptoms } \\
\downarrow \text { interpersonal sensitivity } \\
\downarrow \text { hostility } \\
\uparrow \text { global functioning }\end{array}$ & [36 \\
\hline Tritt et al. (2005) & $\begin{array}{l}\text { Lamotrigine } \\
(50-200 \mathrm{mg} / \text { day }) \\
\text { versus placebo }\end{array}$ & $\begin{array}{l}\mathrm{RCT} \\
8 \text { weeks }\end{array}$ & 24 female BPD patients & $\downarrow$ anger & [38] \\
\hline $\begin{array}{l}\text { Reich et al. } \\
\text { (2009) }\end{array}$ & $\begin{array}{l}\text { Lamotrigine } \\
(25-275 \mathrm{mg} / \mathrm{day}) \\
\text { versus placebo }\end{array}$ & $\begin{array}{l}\mathrm{RCT} \\
12 \text { weeks }\end{array}$ & $\begin{array}{l}28 \text { BPD patients with major } \\
\text { depression and anxiety } \\
\text { disorders }\end{array}$ & $\begin{array}{l}\downarrow \text { impulsivity } \\
\downarrow \text { affective instability }\end{array}$ & [40] \\
\hline
\end{tabular}

Topiramate

Topiramate has also been investigated to test its ability to control aggressive behaviors in BPD patients.

In the first RCT by Nickel et al. [31], 31 women with BPD were treated with topiramate (50-250 mg/day) or placebo for 8 weeks. Topiramate was superior to placebo with respect to most of the State-Trait Anger Expression Inventory (STAXI) scales. The second topiramate RCT by the same group [32] included 42 male patients and obtained approximately the same results.

Follow-up studies performed by these authors [33-36] found that topiramate was a safe agent with long-lasting effects in reducing aggression in BPD.

A third RCT on topiramate (25-200 mg/day for 10 weeks) was performed by Loew et al. in 56 females with BPD and concurrent mood disorders, finding a significant decrease of somatization symptoms, interpersonal sensitivity, and hostility and an improvement of global functioning [37].

\section{Lamotrigine}

To date, only two double-blind trials of lamotrigine in BPD are available. In 2005, Tritt et al. assessed the efficacy of lamotrigine (titrated to a dose of $200 \mathrm{mg} /$ day) versus placebo in the treatment of aggression in 24 female BPD outpatients [38]. The study found a significant improvement of anger after 8 weeks of treatment. Moreover, during the 18-month follow-up observation, significant changes of all the scales of the STAXI were reported in the lamotrigine-treated subjects [39].

Reich et al. performed a 12-week double-blind placebo-controlled study of 28 BPD patients, 
in order to evaluate the efficacy of lamotrigine in the treatment of affective instability [40]. A significantly greater reduction of affective instability and impulsivity was found in the group with lamotrigine.

In conclusion, available studies provide initial evidence that the mood stabilizers topiramate, valproate and lamotrigine can be useful for the treatment of affective symptoms related to anger and impulsive-aggression in BPD patients.

\section{- Antipsychotics}

Antipsychotics are widely used in clinical practice for treatment of BPD patients. RCTs have been performed both for classical neuroleptics and new generation antipsychotics, considering effects not only on psychotic or psychotic-like symptoms, but also on different dimensions of BPD psychopathology (Table 4).

\section{Classical neuroleptics}

Since the 1980s, many RCTs have been conducted to test the efficacy of neuroleptics such as flupentixol decanoate [41], loxapine, chlorpromazine [42], thiothixene [8], trifluoperazine [16], and haloperidol $[17,43]$ in BPD patients.

In 1993, Soloff et al. performed a 5-week RCT of haloperidol ( $4 \mathrm{mg} / \mathrm{day}$ ) versus the MAOI phenelzine $(60 \mathrm{mg} / \mathrm{day})$ and placebo in a large sample of BPD inpatients $(n=108)$, finding that haloperidol efficacy was limited to hostility and impulsive-aggressive behaviors [18] Cornelius et al. followed the 54 responders of these 108 patients in a continuation study lasting 16 weeks [44]. Haloperidol was prescribed up to a maximum of $6 \mathrm{mg} / \mathrm{day}$, but failed to obtain significant effects. During prolonged haloperidol treatment, depression significantly increased in severity and global clinical improvement was modest, limited to irritability. Moreover, 64\% of patients in the haloperidol group dropped out during follow-up.

In conclusion, classical neuroleptics might be administered to BPD patients during acute states with anger and psychotic-like symptoms, but evidence of efficacy is poor, and treatment should be administrated in low doses and for short periods because of common and remarkable adverse effects (extrapyramidal symptoms).

\section{New generation antipsychotics}

Several open-label studies with risperidone, clozapine, and quetiapine have shown considerable effects on cognitive-perceptual symptoms, anger, and impulsivity in BPD patients. However, only olanzapine, aripiprazole and ziprazidone have been tested in RCTs.

\section{Olanzapine}

Olanzapine has been the most thoroughly studied atypical antipsychotic in the treatment of BPD. Three studies investigated the effects of olanzapine compared with placebo.

Zanarini and Frankenburg performed a 6-month RCT of olanzapine (mean dose $5.33 \mathrm{mg} /$ day) in 28 women with BPD [45]. A significant improvement over placebo was reported in a wide range of symptoms, including interpersonal sensitivity, anxiety, anger, hostility, paranoia, psychoticism and global functioning.

Bogenschutz and Nurnberg investigated the efficacy of olanzapine $(5-10 \mathrm{mg} /$ day $)$ in 40 BPD subjects during a 12-week RCT [46]. They observed a significant improvement with the CGI scale modified for BPD, but not with the Symptom Checklist-90 subscales.

In another RCT performed by Schulz et al., 314 patients were randomly assigned to olanzapine $(2.5-20 \mathrm{mg} / \mathrm{day})$ or placebo for 12 weeks [47]. Both groups showed a significant improvement of BPD symptomatology (Zanarini Rating Scale for BPD) and did not differ at end point. However, time to response was significantly shorter for olanzapine.

In recent years, studies comparing olanzapine with other active drugs, psychotherapy, or their combination have been published.

The study by Zanarini et al. comparing the efficacy of olanzapine (mean dose $3.3 \mathrm{mg} /$ day), fluoxetine, and their combination has already been described [24].

Soler et al. [48] reported a 12-week trial of olanzapine (mean dose $8.83 \mathrm{mg} /$ day) versus placebo in 60 BPD outpatients, who received a concomitant psychotherapy with DBT. Olanzapine was superior to placebo in reducing anxiety, depressive symptoms and impulsive-aggressive behaviors. In a following study with a similar design, Linehan et al. included 24 women with BPD, who were randomly assigned to receive olanzapine (mean dosage $5 \mathrm{mg} / \mathrm{day}$ ) plus DBT or placebo plus DBT for 21 weeks [49]. Both groups of patients showed a considerable improvement of irritability, aggression, depressive symptoms, and self-injury, but irritability and aggression scores decreased more quickly in the olanzapine group. 


\begin{tabular}{|c|c|c|c|c|c|}
\hline Study (year) & Agents & Study design & Subjects & Results (primary outcome) & Ref. \\
\hline Soloff et al. (1993) & $\begin{array}{l}\text { Haloperidol ( } 4 \mathrm{mg} / \text { day) versus } \\
\text { phenelzine }(60 \mathrm{mg} / \text { day }) \\
\text { versus placebo }\end{array}$ & $\begin{array}{l}\mathrm{RCT} \\
5 \text { weeks }\end{array}$ & $\begin{array}{l}108 \text { BPD inpatients } \\
\text { with concomitant } \\
\text { major depression }\end{array}$ & $\begin{array}{l}\downarrow \text { hostility } \\
\downarrow \text { impulsive-aggression }\end{array}$ & [18] \\
\hline Cornelius et al. (1993) & $\begin{array}{l}\text { Haloperidol ( } \leq 6 \mathrm{mg} / \text { day) } \\
\text { versus placebo }\end{array}$ & $\begin{array}{l}\mathrm{RCT} \\
16 \text { weeks }\end{array}$ & $\begin{array}{l}54 \text { BPD outpatients, } \\
\text { responders from the } \\
\text { study by Soloff et al. }\end{array}$ & $\downarrow$ irritability & [44] \\
\hline $\begin{array}{l}\text { Zanarini and } \\
\text { Frankenburg (2001) }\end{array}$ & $\begin{array}{l}\text { Olanzapine ( } 5.33 \text { mg/day) } \\
\text { versus placebo }\end{array}$ & $\begin{array}{l}\mathrm{RCT} \\
6 \text { months }\end{array}$ & 28 female BPD patients & $\begin{array}{l}\downarrow \text { anger } \\
\downarrow \text { interpersonal sensitivity } \\
\downarrow \text { anxiety } \\
\downarrow \text { paranoid ideation } \\
\uparrow \text { global functioning }\end{array}$ & {$[45]$} \\
\hline $\begin{array}{l}\text { Bogenschutz and } \\
\text { Nurnberg (2004) }\end{array}$ & $\begin{array}{l}\text { Olanzapine (5-10 mg/day) } \\
\text { versus placebo }\end{array}$ & $\begin{array}{l}\text { RCT } \\
12 \text { weeks }\end{array}$ & 40 BPD outpatients & $\begin{array}{l}\downarrow \text { anger } \\
\downarrow \text { global symptoms }\end{array}$ & {$[46]$} \\
\hline Schulz et al. (2008) & $\begin{array}{l}\text { Olanzapine }(2.5-20.0 \mathrm{mg} / \text { day }) \\
\text { versus placebo }\end{array}$ & $\begin{array}{l}\mathrm{RCT} \\
12 \text { weeks }\end{array}$ & 314 BPD patients & $\begin{array}{l}\text { No significant differences of } \\
\text { BPD symptoms } \\
\text { Faster } \downarrow \text { BPD severity in olanzapine } \\
\text { group }\end{array}$ & {$[47]$} \\
\hline Soler et al. (2005) & $\begin{array}{l}\text { Olanzapine }(5-20 \mathrm{mg} / \text { day })+ \\
\text { DBT versus DBT + placebo }\end{array}$ & $\begin{array}{l}\mathrm{RCT} \\
12 \text { weeks }\end{array}$ & 60 BPD patients & $\begin{array}{l}\downarrow \text { anxiety } \\
\downarrow \text { depression } \\
\downarrow \text { impulsive-aggression }\end{array}$ & {$[48]$} \\
\hline Linehan et al. (2008) & $\begin{array}{l}\text { Olanzapine ( } 5 \mathrm{mg} / \text { day })+\mathrm{DBT} \\
\text { versus DBT + placebo }\end{array}$ & $\begin{array}{l}\text { RCT } \\
21 \text { weeks }\end{array}$ & 24 female BPD patients & $\begin{array}{l}\text { No significant differences of } \\
\text { general symptoms } \\
\text { Faster } \downarrow \text { irritability and aggression in } \\
\text { the olanzapine group }\end{array}$ & {$[49]$} \\
\hline $\begin{array}{l}\text { Shafti and Shahveisi } \\
\text { (2010) }\end{array}$ & $\begin{array}{l}\text { Olanzapine ( } 7 \mathrm{mg} / \mathrm{day}) \\
\text { versus haloperidol ( } 7 \mathrm{mg} / \text { day) }\end{array}$ & $\begin{array}{l}\mathrm{RCT} \\
8 \text { weeks }\end{array}$ & $\begin{array}{l}28 \text { female BPD } \\
\text { inpatients }\end{array}$ & $\begin{array}{l}\text { No significant differences of generic } \\
\text { behavioral symptoms }\end{array}$ & {$[50]$} \\
\hline Nickel et al. (2006) & $\begin{array}{l}\text { Aripiprazole ( } 15 \mathrm{mg} / \text { day }) \\
\text { versus placebo }\end{array}$ & $\begin{array}{l}\mathrm{RCT} \\
8 \text { weeks }\end{array}$ & 57 BPD patients & $\begin{array}{l}\downarrow \text { depression and anxiety } \\
\downarrow \text { anger } \\
\downarrow \text { aggressiveness } \\
\downarrow \text { paranoia } \\
\uparrow \text { global functioning }\end{array}$ & {$[51]$} \\
\hline Pascual et al. (2008) & $\begin{array}{l}\text { Ziprasidone ( } 84 \mathrm{mg} / \text { day) } \\
\text { versus placebo }\end{array}$ & $\begin{array}{l}\mathrm{RCT} \\
12 \text { weeks }\end{array}$ & 60 BPD patients & $\begin{array}{l}\text { No effects on psychoticism, } \\
\text { depression, anxiety, impulsivity } \\
\text { and hostility }\end{array}$ & {$[53]$} \\
\hline
\end{tabular}

In a recent 8 -week double-blind study comparing olanzapine (mean dose $7 \mathrm{mg} /$ day) with haloperidol (mean dose $7 \mathrm{mg} /$ day) in 28 female inpatients with BPD, Shafti and Shahveisi did not find significant differences between drugs in reducing the severity of generic behavioral symptoms (anxiety, depressive mood and hostility subscales of the Brief Psychiatric Rating Scale) [50]. It must be noted that this trial did not use a control group with placebo.

\section{Aripiprazole}

The only RCT of aripiprazole (15 mg/day) was performed by Nickel et al. in 57 BPD patients, and found significant effects on psychotic symptoms, depression, anxiety and hostility after
8 weeks [51]. Improvements were confirmed in an 18-month follow-up observation study [52].

\section{Ziprasidone}

Pascual et al. included $60 \mathrm{BPD}$ patients in a 12-week placebo-controlled trial to test efficacy of ziprasidone (mean dose $84 \mathrm{mg} /$ day) on psychoticism, depression, anxiety, impulsivity and hostility [53]. The study failed to show any significant effect of ziprasidone in this sample.

In conclusion, there is growing evidence that the atypical antipsychotic olanzapine significantly improves cognitive symptoms, aggressiveness, anxiety and depression in BPD samples. Further studies are required to test the efficacy of newer drugs, such as aripiprazole. 


\section{- Other agents}

Other psychotropic agents, such as opiate antagonists and omega- 3 fatty acids, have been tested for their efficacy regarding symptoms of BPD (Table 5).

One small double-blind study, including nine BPD patients, failed to show efficacy of intravenous administration of naloxone $(0.4 \mathrm{mg})$ in the treatment of acute dissociative states [54].

Zanarini and Frankenberg investigated the effects of omega-3 fatty acids in the treatment of 30 female BPD patients [55]. They reported significant improvements in depressive symptoms and aggressive behaviors in response to ethyl-eicosapentaenoic acid ( $1 \mathrm{~g} /$ day) compared with placebo in an 8-week RCT. Hallahan et al. performed a second study evaluating 49 subjects with self-harm behaviors (35 with a diagnosis of BPD) in a 12-week RCT [56]. Patients were randomized to receive eicosapentaenoic acid (1.2 g) plus docosahexaenoic acid (0.9 g) versus placebo, in addition to standard psychiatric care. The group receiving omega-3 fatty acids had significantly greater improvements in scales for depression, suicidality and reaction to daily stresses.

In conclusion, the results of these two studies are promising for treatment of mood symptoms and aggressive behaviors in BPD patients, in particular, considering the good tolerability of these agents.

\section{Treatment of antisocial PD}

Studies investigating the pharmacological treatment of ASPD are scarce and involve heterogeneous samples (Table 6). Eight trials have been performed, but none of them included patients only on the basis of having ASPD. Most studies are oriented around the treatment of drug or alcohol abuse in ASPD patients, while no study focused on the disorder itself.
Drugs compared with placebo belong to four categories:

- Antiepileptics: one investigation has been conducted using carbamazepine [57], at a dose of $450 \mathrm{mg} /$ day for incarcerated men with aggression. No data were available for the ASPD subgroup in this trial. Three studies have been performed with phenytoin [57-59] at a dose of $300 \mathrm{mg} /$ day. Barratt reported that phenytoin is more effective than placebo for reducing frequency and intensity of aggressive behaviors in 126 male prisoners with impulsiveaggression [58]. No separate results about symptoms of ASPD are provided by the other two studies [57,59]. Two controlled trials [57,60] compared efficacy of valproate with placebo in outpatients with aggression, but neither reported significant findings in the ASPD group.

- Antidepressants: two RCTs investigated the efficacy of desipramine. The first [61] included methadone-maintained inpatients with opioid and cocaine dependency, the other [62] involved methadone-maintained outpatients with sole cocaine dependence. Desipramine was not found superior to placebo in either study. The trial performed by Powell [63] in a sample of 20 men with alcohol dependence, reported the efficacy of nortriptyline (25-75 $\mathrm{mg} /$ day) in reducing mean number of drinking days, level of anxiety, and alcohol dependence, but not the severity of alcohol misuse.

- Dopamine agonists: two controlled trials have been published on amantadine and bromocriptine. In the first study [61], amantadine was not found superior to placebo in men with opioid and cocaine dependency. The study on bromocriptine [63] reported the efficacy of this drug at $15 \mathrm{mg} /$ day on anxiety symptoms of 18 men with alcohol dependency.

Table 5. Double-blind randomized trials of opiate antagonists and omega-3 fatty acids in the treatment of borderline personality disorder.

\begin{tabular}{|c|c|c|c|c|}
\hline Study (year) & Agents & Study design & Subjects & Results (primary outcome) \\
\hline $\begin{array}{l}\text { Philipsen et al. } \\
\text { (2004) }\end{array}$ & $\begin{array}{l}\text { Naloxone iv. }(0.4 \mathrm{mg}) \text { versus } \\
\text { placebo }\end{array}$ & $\mathrm{RCT}$ & 9 BPD patients & $\begin{array}{l}\text { No different effects on } \\
\text { dissociative symptoms }\end{array}$ \\
\hline $\begin{array}{l}\text { Zanarini and } \\
\text { Frankenberg (2003) }\end{array}$ & $\begin{array}{l}\text { Ethyl-eicosapentaenoic acid } \\
\text { (1 g/day) versus placebo }\end{array}$ & $\begin{array}{l}\text { RCT } \\
8 \text { weeks }\end{array}$ & 30 female BPD patients & $\begin{array}{l}\downarrow \text { depressive symptoms } \\
\downarrow \text { aggressive behaviors }\end{array}$ \\
\hline Hallahan et al. (2007) & $\begin{array}{l}\text { Eicosapentaenoic acid ( } 1.2 \mathrm{~g} / \text { day }) \\
\text { plus docosahexaenoic acid } \\
\text { ( } 0.9 \mathrm{~g} / \text { day }) \text { versus placebo }\end{array}$ & $\begin{array}{l}\mathrm{RCT} \\
12 \text { weeks }\end{array}$ & $\begin{array}{l}49 \text { subjects with self-harm } \\
\text { behaviors } \\
\text { (35 BPD patients) }\end{array}$ & $\begin{array}{l}\downarrow \text { depression and suicidality } \\
\downarrow \text { reaction to daily stresses }\end{array}$ \\
\hline
\end{tabular}


Table 6. Double-blind randomized trials in the treatment of antisocial personality disorder.

\begin{tabular}{|c|c|c|c|c|}
\hline Study (year) & Agents & Study design & Subjects & Results \\
\hline $\begin{array}{l}\text { Barratt et al. } \\
\text { (1997) }\end{array}$ & $\begin{array}{l}\text { Phenytoin ( } 300 \text { mg/day) } \\
\text { versus placebo }\end{array}$ & $\begin{array}{l}\text { RCT } \\
9 \text { weeks }\end{array}$ & $\begin{array}{l}126 \text { male prisoners with } \\
\text { impulsive-aggression }\end{array}$ & $\downarrow$ aggressive behaviors \\
\hline $\begin{array}{l}\text { Powell et al. } \\
\text { (1995) }\end{array}$ & $\begin{array}{l}\text { Nortriptyline ( } 25-75 \mathrm{mg} / \text { day) } \\
\text { versus bromocriptine } \\
\text { ( } 15 \mathrm{mg} / \text { day) } \\
\text { versus placebo }\end{array}$ & $\begin{array}{l}\mathrm{RCT} \\
4 \text { weeks }\end{array}$ & $\begin{array}{l}38 \text { male ASPD with } \\
\text { alcohol dependence }\end{array}$ & $\begin{array}{l}\downarrow \text { drinking days, level of anxiety } \\
\text { and alcohol dependence in the } \\
\text { nortriptyline group } \\
\downarrow \text { anxiety symptoms in the } \\
\text { bromocriptine group }\end{array}$ \\
\hline
\end{tabular}

- Opioid antagonists: only one study on naltrexone is available in this category [64]. The authors compared subgroups of alcohol dependents with and without ASPD or BPD and concluded that "diagnosis of PD did not adversely affect alcohol outcomes, and patients with ASPD or BPD did not have a poorer response to medication" [64].

In summary, it is difficult to draw any conclusion about ASPD treatment from the data available in the literature. Only three drugs (nortriptyline, bromocriptine and phenytoin) were found superior to placebo. There is some evidence that nortriptyline could be useful in decreasing alcohol abuse of ASPD patients and both nortriptyline and bromocriptine are effective on anxiety symptoms in individuals with ASPD and alcohol dependency. There is also some evidence that phenytoin controls impulsive-aggressive behaviors in ASPD subjects. However, it remains unclear whether any drugs are effective in the treatment of core features of this PD.

\section{Pharmacotherapy of cluster C PDs \\ - Treatment of avoidant PD}

To date, no RCTs on pharmacological treatment of patients with cluster C PDs have been published. Nevertheless, the treatment guidelines of the World Federation of Societies of Biological Psychiatry (WFSBP) [65] indicated the efficacy of antidepressants (SSRIs, SNRIs and MAOIs) for anxious/avoidant PD, on the basis of data concerning Axis I anxiety disorders like social phobia.

\section{- Treatment guidelines \& meta-analyses} In 2001, the APA published the first set of guidelines for the treatment of borderline PD, proposing a pharmacotherapy targeted at three symptom dimensions: affective dysregulation, impulsive-behavioral dyscontrol and cognitiveperceptual symptoms. APA guidelines and following updates $[1,66]$ recommended to choose antidepressant agents (SSRIs and MAOIs) and mood stabilizers as first- and second-line interventions for affective dysregulation, SSRIs and mood stabilizers for impulsive-behavioral dyscontrol, and antipsychotics as first-line therapy for cognitive-perceptual symptoms.

In 2007, an International Task Force of the WFSBP [65] developed practical guidelines for the biological treatment of three PDs: borderline, schizotypal and anxious/avoidant. The authors considered the evidence levels of each class of medications: level A, good researchbased evidence (at least three RCTs); level B, fair research-based evidence (at least two RCTs or one RCT and $\geq 1$ prospective, large, openlabel study); level $\mathrm{C}$, minimal research-based evidence (one RCT and one prospective, openlabel study/case series or at least two prospective, open-label studies/case series); level D, expert opinion based. The WFSBP Task Force recommended atypical antipsychotics for STPD (evidence level $\mathrm{C}$ ) and antidepressants for anxious/avoidant PD (evidence level A), basing these indications only on data concerning Axis I anxiety disorders, like social phobia.

Concerning BPD treatment, only evidence level $\mathrm{C}$ is achieved for antidepressants and mood stabilizers, while the efficacy of secondgeneration antipsychotics is indicated on a fair research-based evidence level (level B).

Guidelines from NICE on management of borderline and antisocial PDs [101,102] have a more prudent position and do not recommend drug therapy other than for treatment of mental disorders in comorbidity. So, they reach different conclusions from other guidelines, despite considering approximately the same evidence. A reason for this discordance is that the NICE group graded available evidence as 'low quality'. 
Moreover, the NICE guidelines have been developed looking at the care pathway within the NHS in England and Wales, considering evidence of cost-effectiveness (including evidence of harm) not only for medications, but also for the whole range of treatments (clinical management and psychological therapies) [67].

Recently, following the growing number of pharmacological trials in patients with BPD, a few meta-analyses on BPD treatment have been published. One was performed by the Cochrane Collaboration [68] and included ten RCTs published between 1980 and 2001, predominantly on classical antipsychotics and antidepressants. These authors did not find a good level of evidence for medication efficacy in BPD. In the same year, a meta-analysis by Nosè $e t$ al. on 22 RCTs concluded that antidepressants and mood stabilizers are effective against affective instability and anger, while antipsychotics have positive effects on impulsive-aggressive behaviors and global functioning [69]. In the systematic review by Duggan et al. on the pharmacological treatment of PDs, efficacy of atypical antipsychotics and mood stabilizers in improving cognitive-perceptual symptoms and impulsivity aggression, respectively, was reported [70]. Recently, results of meta-analyses and conclusions of systematic reviews have indicated a noticeable shift from the choice of antidepressants to mood stabilizers and secondgeneration antipsychotics in the treatment of BPD [71]. Few reviews tried to summarize available data providing indications focused on APA or similar dimensions of BPD psychopathology.

In a meta-analysis concerning efficacy of medications on anger and depression in BPD patients, Mercer et al. suggested that mood stabilizers should be considered as first-line therapy for anger and affective symptoms, rather than SSRIs [72]. Antipsychotics were found to have a medium effect on symptoms of anger and no effects on depression. Ingenhoven $e t a l$. evaluated the efficacy of pharmacotherapy for borderline and schizotypal PDs on specific target domains: cognitive-perceptual symptoms, impulsive-behavioral dyscontrol, affective dysregulation (depressed mood, anxiety, anger and mood lability) and global functioning [73]. Mood stabilizers had positive effects on global functioning, impulsive-behavioral dyscontrol, anger and anxiety. Antipsychotics had a moderate effect on cognitive symptoms and anger. Antidepressants were not found to be effective on impulsive-behavioral dyscontrol and mood symptoms, but they had a small effect on anxiety and anger. Saunders and Silk collected and analyzed data from placebo-controlled trials on treatment of BPD, sorting target symptoms into the trait dimensions of affective instability, anxiety inhibition, cognitive-perceptual disturbances and impulsivity aggression [74]. They found that antipsychotics had the strongest evidence for all dimensions.

According to the Cochrane Systematic Review of pharmacological interventions for BPD [75], the available evidence indicates that mood stabilizers, second-generation antipsychotics, and omega-3 fatty acids may be effective for treating specific BPD symptoms. The use of antidepressants is supported by data only in patients with concomitant depression.

Findings from these studies raise considerable questions on the decisional trees proposed by APA guidelines [1]. In particular, the recommendation to administer SSRIs or related antidepressants to treat affective dysregulation and impulsive-behavioral dyscontrol should be reconsidered on the basis of more recent results.

\section{Conclusion \& future perspective}

In recent years a growing number of trials on the pharmacological treatment of PDs, in particular of BPD, have been performed. Nevertheless, available studies from important methodological limitations, such as a small number of patients, samples made of only male or female gender, heterogeneous selection criteria and outcome measures, and high rates of drop-outs. Moreover, the duration of trials is usually short and no conclusions can be drawn on the long-term use of medications in these patients.

Despite these limitations, the review of the RCTs published from 1990 to 2010 provided some evidence of the efficacy of certain medications to treat specific symptoms of borderline PDs. Proposing indications on drug treatment of other PDs is more difficult and poorly reliable because available data are sparse.

Preliminary studies performed with antipsychotics in patients with schizotypal PD suggested a reduction of psychotic-like symptoms.

However, some subjects included in these trials had concomitant BPD and it remains unclear whether reported improvements were due to the effects of medications on BPD-related 
symptoms. Furthermore, drugs were used at low doses to minimize considerable sensitivity to side effects in this population. Although antipsychotics may reduce clinical symptoms, they do not induce a substantial benefit for cognitive performance of individuals with STPD. Recent trials suggested an improvement of cognitive performance in these patients (e.g., working memory and context processing) using dopamine and adrenaline agonists, but these agents are not currently used in clinical practice.

Concerning treatment of antisocial PD, there is initial evidence that nortriptyline and bromocriptine could produce some effects in individuals with concurrent alcohol dependence, while phenytoin seems to reduce impulsive-aggressive behaviors. However, it is questionable whether any drug is effective in the treatment of core features of ASPD.

Investigations on psychotropic agents in the treatment of BPD have recently tested several drugs belonging to the classes of antidepressants, mood stabilizers and antipsychotics.

In summary, there is some evidence that SSRIs are effective in decreasing depressed mood, anxiety, and anger in BPD patients, in particular when comorbidity with affective disorders is present. Many authors retain that prescription of SSRIs should be reserved for treatment of a comorbid major depressive episode, rather than BPD affective dysregulation itself $[65,73,75]$. Effects of SSRIs on impulsiveaggression have less support and may be limited to male gender. Concerning mood stabilizers, available studies provide evidence that topiramate, valproate and lamotrigine can be useful for the treatment of affective symptoms related to anger and impulsive-behavioral dyscontrol in BPD patients. These agents also appear to have significant effects on global functioning. As for second-generation antipsychotics, there is growing evidence from RCTs that olanzapine significantly improves cognitive symptoms, anger, anxiety and depression in BPD. Further controlled studies are needed to confirm the efficacy of newer drugs, such as aripiprazole.

Balancing the evidence of efficacy against adverse effects, some authors retain that dietary supplementation by omega-3 fatty acids could also be considered as an option to treat mood symptoms and impulsive-aggressive behaviors.

In conclusion, a pharmacotherapy targeted on well-defined symptom domains of BPD can be effective in improving some features of the clinical picture, but no medication is indicated to perform a global treatment of the disorder itself.

Most clinical trials testing the efficacy of drugs in BPD patients provide results on change of single symptoms or clusters of symptoms. Even if APA guidelines recommend a dimensional treatment of $\mathrm{BPD}$, dimensions are usually not considered in single trials, mainly because authors do not choose dimensional instruments to evaluate outcome. There is the need for a more clear distinction of the two concepts of symptoms and dimensions in both research and clinical application.

Concerning the applicability of data from RCTs to clinical practice, we should not underestimate the differences between study samples and clinical populations. In fact, patients in clinical populations are not selected on the basis of inclusion/exclusion criteria. So, the level of social dysfunction and the frequency of Axis I and II comorbidity (in particular with mood disorders) are likely higher in usual practice. Moreover, patients with PDs present impulsivebehavioral dyscontrol and poor compliance and adherence. Therefore, clinicians prescribing medications should carefully inform and monitor them, in order to minimize the risk of intoxication, abuse, self-poisoning and side effects. As stated in the NICE guidelines and reported in a previous review by our group [76], some of the drugs administered to PD patients are potentially harmful: for example, valproate semisodium is potentially dangerous for women of child-bearing age, who are the largest proportion of BPD patients in clinical practice and often do not adopt adequate birth control methods; and antipsychotics can induce serious neurological and metabolic side effects [67]. It should also be stressed that drugs potentially fatal in overdose must be used with great caution in PD patients at risk of suicide [1]. Thus, tolerability profile, characteristics of patients and evidence of efficacy should be carefully examined and balanced before prescribing medications to PD patients. Another remarkable difference between trials and clinical practice is that patients included in study samples are usually treated with selected doses of a single therapeutic agent, while those observed in the usual clinical settings are more commonly treated with multiple medications and psychotherapy at the same time. So, further investigations focused on associations of drugs 
and combination of medications and psychosocial interventions are required to collect data that can be more easily and reliably applied to everyday patients.

As repeatedly suggested in this article and by others [70-74], future perspectives of research should focus on a series of core topics: largescale multicenter RCTs of mood stabilizers and new antipsychotics in order to confirm preliminary evidence; drug-to-drug comparisons (e.g., atypical vs traditional antipsychotics, different mood stabilizers) to explore differential effects of medications; fixed-dosage and long-term studies in order to determine appropriate doses and duration of treatments; identification of biological, clinical and pharmacological factors that predict response to drug treatments; assessment of results of combined therapy in comparison with single pharmaco- and psychotherapy; and selection of a set of outcome measures that can be retained reliable and specific to test drug efficacy and safety in BPD populations.

\section{Financial \& competing interests disclosure}

The authors have no relevant affiliations or financial involvement with any organization or entity with a financial interest in or financial conflict with the subject matter or materials discussed in the manuscript. This includes employment, consultancies, honoraria, stock ownership or options, expert testimony, grants or patents received or pending, or royalties.

No writing assistance was utilized in the production of this manuscript.

\section{Bibliography}

Papers of special note have been highlighted as:

- of interest

- of considerable interest

1 American Psychiatric Association: Practice guideline for the treatment of patients with borderline personality disorder. Am. J. Psychiatry. 158, 1-52 (2001).

- The first published guidelines on treatment of a personality disorder.

2 Siever LJ, Davis KL: A psychobiological perspective on the personality disorders. $\mathrm{Am}$. J. Psychiatry 148, 1647-1658 (1991).

3 Soloff PH: Algorithms for pharmacological treatment of personality dimensions: symptom-specific treatments for cognitiveperceptual, affective, and impulsivebehavioral dysregulation. Bull. Menninger. Clin. 62(2), 195-214 (1998).

4 Soloff PH: Psychopharmacology of borderline personality disorder. Psychiatr. Clin. North Am. 23, 169-192 (2000).

5 Battaglia M, Torgersen S: Schizotypal disorder: at the crossroads of genetics and nosology. Acta Psychiatr. Scand. 24(5), 303-310 (1996).

6 Cadenhead KS, Light GA, Geyer MA, McDowell JE, Braff DL: Neurobiological measures of schizotypal personality disorder: defining an inhibitory endophenotype? Am. J. Psychiatry 159(5), 869-871 (2002).

7 Montgomery SA, Montgomery D: Pharmacological prevention of suicidal behaviour. J. Affect. Disord. 4, 291-298 (1982).
8 Goldberg SC, Schulz SC, Schulz PM, Resnick RJ, Hamer RM, Friedel RO: Borderline and schizotypal personality disorder treated with low-dose thiothixene vs placebo. Arch. Gen. Psychiatry 43, 680-686 (1986).

9 Soloff PH, George A, Nathan S, Schulz PM, Ulrich RF, Perel JM: Amitriptyline and haloperidol in unstable and schizotypal borderline disorders. Psychopharmacol. Bull. 22(1), 177-182 (1986).

10 Schulz SC, Camlin KL, Berry SA, Jesberger JA: Olanzapine safety and efficacy in patients with borderline personality disorder and comorbid dysthymia. Biol. Psychiatry 46, 1429-1435 (1999).

11 Keshavan M, Shad M, Soloff P, Schooler N: Efficacy and tolerability of olanzapine in the treatment of schizotypal personality disorder. Schizophr. Res. 71(1), 197-101 (2004).

12 Koenigsberg HW, Reynolds D, Goodman M et al.: Risperidone in the treatment of schizotypal personality disorder. J. Clin. Psychiatry 64(6), 628-342 (2003).

13 McClure MM, Koenigsberg HW, Reynolds D et al.: The effects of risperidone on the cognitive performance of individuals with schizotypal personality disorder. J. Clin. Psychopharmacol. 29(4), 396-398 (2009).

14 McClure MM, Barch DM, Romero MJ et al: The effects of guanfacine on context processing abnormalities in schizotypal personality disorder. Biol. Psychiatry 15, 61(10), 1157-1160 (2007).

15 McClure MM, Harvey PD, Goodman M et al.: Pergolide treatment of cognitive deficits associated with schizotypal personality disorder: continued evidence of the importance of the dopamine system in the schizophrenia spectrum.

Neuropsychopharmacology 35(6), 1356-1362 (2010).

16 Cowdry RW, Gardner DL: Pharmacotherapy of borderline personality disorder. Alprazolam, carbamazepine, trifluoperazine, and tranylcypromine. Arch. Gen. Psychiatry 45, 111-119 (1988).

17 Soloff $\mathrm{PH}$, George A, Nathan S et al.: Progress in pharmachotherapy of borderline disorders. A double blind study of amitriptyline, haloperidol, and placebo. Arch. Gen. Psychiatry 43, 691-697 (1986).

18 Soloff PH, Cornelius J, George A, Nathan S, Perel JM, Ulrich RF: Efficacy of phenelzine and haloperidol in borderline personality disorder. Arch. Gen. Psychiatry 50, 377-385 (1993).

19 Links P, Steiner M, Boiago I, Irwin D: Lithium therapy for borderline patients: preliminary findings. J. Personal. Disord. 4 , 173-181 (1990).

20 Markovitz P: Pharmacotherapy of impulsivity, aggression, and related disorders. In: Impulsivity and Aggression. Hollander E, Stein DJ (Eds). John Wiley \& Sons, New York, NY, USA, 263-287 (1995).

21 Salzmann C, Wolfson AN, Schatzberg A et al.: Effect of fluoxetine on anger in symptomatic volunteers with borderline personality disorder. J. Clin. Psychopharmacol. 15, 23-29 (1995).

22 Coccaro EF, Kavoussi RJ: Fluoxetine and impulsive aggressive behaviour in personality disordered subjects. Arch. Gen. Psychiatry 54, 1081-1088 (1997). 
23 Simpson EB, Yen S, Costello E et al: : Combined dialectical behavior therapy and fluoxetine in the treatment of borderline personality disorder. J. Clin. Psychiatry 65(3), 379-385 (2004).

24 Zanarini MC, Frankenburg FR, Parachini EA: A preliminary randomized trial of fluoxetine, olanzapine, and the olanzapinefluoxetine combination in women with borderline personality disorder. J. Clin. Psychiatry 65, 903-907 (2004).

25 Rinne T, van den Brink W, Wouters L, van Dyck R: SSRI treatment of borderline personality disorder: a randomized, placebo-controlled clinical trial for female patients with borderline personality disorder. Am. J. Psychiatry 159(12), 2048-2054 (2002).

26 De la Fuente J, Lotstra F: A trial of carbamazepine in borderline personality disorder. Eur. Neuropsychopharmacol. 4, 479-486 (1994).

27 Hollander E, Allen A, Lopez RP et al: : A preliminary double-blind, placebo-controlled trial of divalproex sodium in borderline personality disorder. J. Clin. Psychiatry 62(3), 199-203 (2001).

28 Hollander E, Tracy KA, Swann AC et al.: Divalproex in the treatment of impulsive aggression: efficacy in cluster B personality disorders. Neuropsychopharmacology 28(6), 1186-1197 (2003).

29 Hollander E, Swann AC, Coccaro EF et al: : Impact of trait impulsivity and state aggression on divalproex versus placebo response in borderline personality disorder. Am. J. Psychiatry 162, 621-624 (2005)

30 Frankenburg FR, Zanarini MC: Divalproex sodium treatment of women with borderline personality disorder and bipolar II disorder: a double-blind placebo-controlled pilot study. J. Clin. Psychiatry 63 (5), 442-446 (2002).

31 Nickel MK, Nickel C, Mitterlehner FO et al:: Topiramate treatment of aggression in female borderline personality disorder patients: a double-blind, placebo-controlled study. J. Clin. Psychiatry 65(11), 1515-1519 (2004).

32 Nickel MK, Nickel C, Kaplan P et al.: Treatment of aggression with topiramate in male borderline patients: a double-blind, placebo-controlled study. Biol. Psychiatry. 57(5), 495-499 (2005).

33 Nickel MK: Topiramate treatment of aggression in male borderline patients. Aust. NZ J. Psychiatry 41(5), 461-462 (2007).

34 Nickel M: Topiramate reduced aggression in female patients with borderline personality disorder. Eur. Arch. Psychiatry Clin. Neurosci. 257(7), 432-433 (2007).
35 Nickel MK, Loew TH: Treatment of aggression with topiramate in male borderline patients, part II: 18-month follow-up. Eur. Psychiatry 23(2), 115-117 (2008).

36 Loew TH, Nickel MK: Topiramate treatment of women with borderline personality disorder, part II: an open 18-month follow-up. J. Clin. Psychopharmacol. 28(3), 355-357 (2008).

37 Loew TH, Nickel MK, Muehlbacher M et al.: Topiramate treatment for women with borderline personality disorder: a double-blind, placebo-controlled study. J. Clin. Psychopharmacol. 26(1), 61-66 (2006).

38 Tritt K, Nickel C, Lahmann C et al.: Lamotrigine treatment of aggression in female borderline-patients: a randomized, doubleblind, placebo-controlled study. J. Psychopharmacol. 19, 287-291 (2005).

39 Leiberich P, Nickel MK, Tritt K, Pedrosa Gil F: Lamotrigine treatment of aggression in female borderline patients, part II: an 18-month follow-up. J. Psychopharmacol. 22(7), 805-808 (2008).

40 Reich DB, Zanarini MC, Bieri KA: A preliminary study of lamotrigine in the treatment of affective instability in borderline personality disorder. Int. Clin. Psychopharmacol. 24(5), 270-275 (2009).

41 Montgomery SA, Montgomery D: Pharmacological prevention of suicidal behaviour. J. Affect. Disord. 4(4), 291-298 (1982).

42 Leone NF: Response of borderline patients to loxapine and chlorpromazine. J. Clin. Psychiatry 43(4), 148-150 (1982).

43 Soloff PH, George A, Nathan S et al.: Amitriptyline versus haloperidol in borderlines: final outcomes and predictors of response. J. Clin. Psychopharmacol. 9, 238-246 (1989).

44 Cornelius JR, Soloff PH, Perel JM, Ulrich RF: Continuation pharmacotherapy of borderline personality disorder with haloperidol and phenelzine. Am. J. Psychiatry 150, 1843-1848 (1993).

45 Zanarini MC, Frankenburg FR: Olanzapine treatment of female borderline personality disorder patients: a double-blind, placebocontrolled pilot study. J. Clin. Psychiatry 62(11), 849-854 (2001).

46 Bogenschutz MP, Nurnberg GH: Olanzapine versus placebo in the treatment of borderline personality disorder. J. Clin. Psychiatry 65, 104-109 (2004).

47 Schulz SC, Zanarini MC, Bateman A et al.: Olanzapine for the treatment of borderline personality disorder: variable dose, 12 -week, randomised double-blind placebo-controlled study. Br. J. Psychiatry 193, 485-492 (2008).
48 Soler J, Pascual JC, Barrachina J et al.: Double-blind, placebo-controlled study of dialectical behavior therapy plus olanzapine for borderline personality disorder. Am. J. Psychiatry 162, 1221-1224 (2005).

49 Linehan MM, McDavid JD, Brown MZ, Sayrs JHR, Gallop RJ: Olanzapine plus dialectical behavior therapy for women with high irritability who meet criteria for borderline personality disorder: a doubleblind, placebo-controlled pilot study. J. Clin. Psychiatry 69(9), 999-1005 (2008).

50 Shafti SS, Shahveisi B: Olanzapine versus haloperidol in the management of borderline personality disorder: a randomized double-blind trial. J. Clin. Psychopharmacol. 30 (1), 44-47 (2010).

51 Nickel MK, Muehlbacher M, Nickel C et al.: Aripiprazole in the treatment of patients with borderline personality disorder: a double-blind, placebo-controlled study. Am. J. Psychiatry 163 (5), 833-838 (2006).

52 Nickel MK, Loew TH, Pedrosa Gil F: Aripiprazole in treatment of borderline patients, part II: an 18-month follow-up. Psychopharmacology 191, 1023-1026 (2007).

53 Pascual JC, Soler J, Puigdemont D et al.: Ziprasidone in the treatment of borderline personality disorder: a double-blind, placebo-controlled, randomized study. J. Clin. Psychiatry 69(4), 603-608 (2008).

54 Philipsen A, Schmahl C, Lieb K: Naloxone in the treatment of acute dissociative states in female patients with borderline personality disorder. Pharmacopsychiatry 37(5), 196-199 (2004).

55 Zanarini MC, Frankenburg FR: Omega-3 fatty acid treatment of women with borderline personality disorder: a doubleblind, placebo-controlled pilot study. Am. J. Psychiatry 160, 167-169 (2003).

56 Hallahan B, Hibblen JR, Davis JM, Garland MR: Omega-3 fatty acid supplementation in patients with recurrent self-harm: single center double-blind randomized controlled trial. Br. J. Psychiatry 190, 118-122 (2007).

57 Stanford MS, Helfritz LE, Conklin SM et al.: A comparison of anticonvulsants in the treatment of impulsive aggression. Exp. Clin. Psychopharmacol. 13(1), 72-77 (2005).

58 Barratt ES, Stanford MS, Felthous AR, Kent TA: The effects of phenytoin on impulsive and premeditated aggression: a controlled study. J. Clin. Psychopharmacol. 17(5), 341-349 (1997). 
59 Stanford MS, Houston RJ, Mathias CW, Greve KW, Villemarette-Pittman NR, Adams D: A double-blind placebo-controlled crossover study of phenytoin in individuals with impulsive aggression. Psychiatry Res. 103(2-3), 193-203 (2001).

60 Hollander E, Tracy KA, Swann AC et al.: Divalproex in the treatment of impulsive aggression: efficacy in cluster B personality disorders. Neuropsychopharmacology 28(6), 1186-1897 (2003).

61 Leal J, Ziedonis D, Kosten T: Antisocial personality disorder as a prognostic factor for pharmacotherapy of cocaine dependence. Drug Alcohol Depend. 35, 31-35 (1994).

62 Arndt IO, McClellan AT, Dorozynsky L, Woody GE, O’Brien CP: Desipramine treatment for cocaine dependence: role of antisocial personality disorder. J. Nerv. Ment. Dis. 182(3), 151-156 (1994).

63 Powell BJ, Campbell JL, Landon JF et al.: A double-blind, placebo-controlled study of nortriptyline and bromocriptine in male alcoholics subtyped by comorbid psychiatric disorders. Alcohol. Clin. Exp. Res. 19(2), 462-468 (1995).

64 Ralevski E, Ball S, Nich C, Limoncelli D, Petrakis I: The impact of personality disorders on alcohol-use outcomes in a pharmacotherapy trial for alcohol dependence and comorbid Axis I disorders. Am. J. Addict. 16(6), 443-449 (2007).

65 Herpertz SC, Zanarini M, Schulz CS, Siever L, Lieb K, Möller HJ: World Federation of Societies of Biological Psychiatry (WFSBP). Guidelines for biological treatment of personality disorders. World J. Biol. Psychiatry 8(4), 212-244 (2007).

- Recent guidelines on pharmacotherapy of schizotypal, borderline and anxious personality disorders.
66 Oldham JM: Guideline watch: practice guideline for the treatment of patients with borderline personality disorder. Presented at: American Psychiatric Association. Arlington, VA, USA 21-26 May 2005.

67 Kendall T, Burbeck R, Bateman A: Pharmacotherapy for borderline personality disorder: NICE guideline. Br. J. Psychiatry 196, 158-159 (2010).

68 Binks C, Fenton M, McCarthy L, Lee T, Adams CE, Duggan C: Pharmacological interventions for people with borderline personality disorder. Cochrane Database Syst. Rev. 1, CD005653 (2006).

69 Nosè M, Cipriani A, Biancosino B, Grassi L, Barbui C: Efficacy of pharmacotherapy against core traits of borderline personality disorder: meta-analysis of randomized controlled trials. Int. Clin. Psychopharmacol. 21(6), 345-353 (2006).

70 Duggan C, Huband N, Smailagic N et al.: The use of pharmacological treatments for people with personality disorder: a systematic review of randomized controlled trials. Pers. Men. Health 2, 119-170 (2008).

71 Abraham PF, Calabrese JR: Evidenced-based pharmacologic treatment of borderline personality disorder: a shift from SSRIs to anticonvulsants and atypical antipsychotics? J. Affect. Disord. 111(1), 21-30 (2008).

72 Mercer D, Douglass AB, Links PS: Metaanalyses of mood stabilizers, antidepressants and antipsychotics in the treatment of borderline personality disorder: effectiveness for depression and anger symptoms. J. Pers. Disord. 23(2), 156-174 (2009).

73 Ingenhoven T, Lafay P, Rinne T, Passchier J, Duivenvoorden $\mathrm{H}$ : Effectiveness of pharmacotherapy for severe personality disorders: meta-analyses of randomized controlled trials. J. Clin. Psychiatry 71(1), 14-25 (2010).
I. Recent meta-analysis of randomized controlled trials of pharmacological treatment of schizotypal and borderline personality disorder.

74 Saunders EFH, Silk KR: Personality trait dimensions and the pharmacological treatment of borderline personality disorder. J. Clin. Psychopharmacol. 29(5), 461-467 (2009).

75 Stoffers J, Völlm BA, Rücker G, Timmer A, Huband N, Lieb K: Pharmacological interventions for borderline personality disorder. Cochrane Database Syst. Rev. 16(6), CD005653 (2010).

- Recent review of randomized controlled trials of pharmacological treatment of borderline personality disorder.

76 Bellino S, Paradiso E, Bogetto F: Efficacy and tolerability of pharmacotherapies for borderline personality disorder. CNS Drugs 22(8), 671-692 (2008).

\section{- Websites}

101 NHS National Institute for Health and Clinical Excellence (NICE): Borderline personality disorder: treatment and management www.guidance.nice.org.uk/CG78

-. Recent guidelines on general management of borderline personality disorder.

102 NHS National Institute for Health and Clinical Excellence (NICE): Antisocial personality disorder: treatment and management www.guidance.nice.org.uk/CG77

- Recent guidelines on general management of antisocial personality disorder. 